\title{
Outcomes of Severe Sepsis among Adults in a Tertiary Care Hospital in Kolkata - A PreliminaryStudy
}

\author{
Sharmila Chatterjee ${ }^{1}$, Amit Chattopadhyay ${ }^{2,3 *}$ and Subhash K Todi ${ }^{1}$ \\ ${ }^{1}$ Advanced Medicare and Research Institute Hospitals (AMRI), India \\ ${ }^{2}$ Case Western Reserve University, Cleveland, USA \\ ${ }^{3}$ MCODS, Manipal Academy of Higher Education, India 1Advanced Medicare and Research Institute Hospitals (AMRI), India \\ ${ }^{2}$ Case Western Reserve University, Cleveland, USA \\ ${ }^{3}$ MCODS, Manipal Academy of Higher Education, India
}

Submission: March 07, 2018; Published: March 27, 2018

*Corresponding author: Department of Oral and Maxillofacial Medicine, Case Western Reserve University School of Dental Medicine, Cleveland, OH, USA, Department of Dental Public Health, Manipal College of Dental Sciences, Mangalore, India, Email: amit.chattopadhyay@case.edu

Abstract

Introduction : A prospective, observational study was conducted in the intensive therapy units (ITU) of an urban tertiary care hospital in Kolkata, India to determine the clinical Association between outcomes and other factors of severe sepsis among adult patients.

Method : All patients admitted to ITU from June 2006 - August 2008 were screened daily for Systemic Inflammatory Response Syndrome (SIRS), organ dysfunction and severe sepsis as defined by the ACCP and SCCM. Association between outcomes and other factors in patient with severe sepsis were analyzed employing t-tests and chi-sq tests.

Results: Out of total of 3,010 ITU admissions, SIRS with organ dysfunction was found in 365 (11.97 \%) patients, of which 234 (66.1\%) were due to severe sepsis. Incidence proportion of severe sepsis was $7.77 \%$ of all ITU admissions. Those severe sepsis patients having received blood transfusion (OR: 2.92), having been on mechanical ventilation (OR: 19.51) and having had a procedure performed in ITU (OR: 10.03) were at greater risk of dying. Mean age, Apache-II score, number of days with mechanical ventilation were higher among those who died, but were not statistically significantly different.

Conclusions: Mortality related to severe sepsis was $8 \%$. ITU mortality was higher compared to data from Western reports. Those receiving blood transfusion, mechanical ventilation and some procedure in ITU were at greater risk of death.

Keywords: Sepsis; Severe; Epidemiology; Outcome; ICU

\section{Introduction}

The World Health Organization and the World Health Assembly have declared sepsis as a public health problem [1]. Sepsis is a major worldwide cause of morbidity and mortality [2] and causes a large burden of disease with negative impact in the community. It is an important cause of admission in the intensive care units (ICU) probably due to more severe illnesses of hospitalized patients and to the persistently high incidence of nosocomial infections. Sepsis is the leading cause of death in non coronary intensive care units [3] and the 10th leading cause of death overall [4]. Despite the availability of potent antibiotics and refined supportive care, the mortality of septic patients remains high with overall estimates to $30 \%$ and increasing to $50 \%$ when associated with shock.

In a study based on 1995 hospital discharge data, Angus etal. [5] estimated that $>750,000$ cases of severe sepsis occur in the United States annually. This is significantly greater than the incidences of the other well recognized diseases such as congestive heart failure [6], death due to cancer of the breast, colon [7], or AIDS
[8]. Several other factors explain this increased incidence of sepsis including the aging population, increasing survival of patients who have cancer or are immunosuppresed and the increasing use of invasive medical interventions. Epidemiologic studies indicate that sepsis or severe sepsis occurs in approximately $2 \%$ of all hospitalizations and in up to $75 \%$ of intensive care unit patients, accounting for as much as $50 \%$ of intensive care unit bed days and carrying mortality rate of $20-80 \%$ [9]. The length of stay for patients with sepsis or severe sepsis is prolonged and both the direct health care costs of hospitalization and economic costs of post sepsis care are extensive [10]. Despite better understanding of sepsis pathophysiology and improved management through multiple modalities, the incidence continues to increase and fatality rates remain unacceptably high.

This high mortality in sepsis has prompted intensive research into the development of new adjunctive therapies in the management of sepsis. Over the past decade, a number of randomized, controlled clinical trials have been conducted 
to test the efficacy of agents modulating the host response to infection. Except the PROWESS study [11], these studies did not show any benefit of the new therapies in terms of survival. These disappointing results could be explained partially by the heterogeneity of patients included in the clinical trial, heterogeneity of infections studied and lack of better knowledge about the pathophysiological mechanisms of sepsis and acute inflammatory response [12]. In recent years, several multicentre studies have presented the epidemiologic data regarding prevalence, mortality, associated risk factors, and outcomes effect of antimicrobial therapy and even cost of severe sepsis globally. India is one of the most populous countries in the world, but epidemiology of severe sepsis within this country is still not well understood.

There remain unanswered basic epidemiologic and health care questions such as estimates in population, incidence, risk factors for the development and outcomes of severe sepsis in the Indian population. Considerable quantities of data on the epidemiology of sepsis are available from the developed world, but there are only few studies which have been conducted on the incidence and demographics of infection in the developing world. Most large epidemiological studies on sepsis have been conducted in North America, Europe and Australia. The general purpose of this overall study is to characterize the epidemiology of sepsis and, to investigate the numbers of adult patients admitted in a multi disciplinary intensive care unit of a tertiary care hospital in eastern India. As a subset, this report aimed to understand the interplay between ICU admission status, clinical status of patients and clinical outcome of severe sepsis.

\section{Methods}

We conducted a large prospective observational study involving 3010 unselected consecutive adult patients admitted to the Intensive therapy unit (ITU) in AMRI Hospitals (43-bedded ITU), Kolkata, India from June, 2006 to August, 2008. The study was reviewed and approved by the Ethical Committee of AMRI Hospitals, Kolkata, India. This centre has a large population of patients, good data management and follows the ACCP/SCCM consensus on the definition and management of severe sepsis. Our study included patients from three ITU's (Medical-Surgical ITU, Neurology ITU and Trauma ITU) in the hospital. All of the ITU's are open units characterized by patient management being supervised by the consultant in-charge of the patient and an expert intensivist available in person and in open view. The Medical-Surgical ITU is also multidisciplinary in nature. The ITU is a tertiary referral unit and is capable of providing comprehensive critical care including complete multi system life support for an indefinite period. The total capacity of the three ITU's include 43 beds (Medical-Surgical ITU= 23, Neurology ITU=10; Trauma ITU=10).

All consecutive adult ITU admissions were assessed for the study (new admissions + readmissions). Patients hospital record charts, lab reports and study specific record sheets were used for obtaining data for the study. Patients who stayed in the ITU for less than 24 hours for routine post-operative surveillance or those who were discharged alive from ITU within 24 hours without developing sepsis or complications were excluded and no further data were collected from them. Patients who stayed in the ITU for 24 hours or longer or developed complications were screened daily for the presence of severe sepsis. The criteria for severe sepsis were the presence of systemic inflammatory response syndrome due to infection described by Bone et al. [13] and the presence of organ dysfunction. Patients who recovered from severe sepsis but remained in the ICU were screened daily for new episodes of severe sepsis. Patients discharged from the ICU and readmitted either within or after the 28 day follow-up period were treated as new admissions.

For this study, other information collected from all patients in the presence of severe sepsis included demographic data (age, sex), admission category (medical, surgical, trauma), the presence of underlying disease (metastatic cancer, hematological malignancy, acquired immunodeficiency syndrome (AIDS) as well as other co-morbidities (cirrhosis of liver, chronic heart failure, diabetes mellitus, chronic renal failure), blood transfusion, mechanical ventilation, procedures conducted in ITU and the duration of stay in the ITU. The Acute Physiology and Chronic Health Evaluation II (APACHE II) score was calculated using worst reading for each variable during 1st 24 hours of ICU admission. For related patients, the worst Glasgow Coma Score was recorded prior to sedation or anaesthesia [13]. All severe sepsis patients were examined daily for assessment of their microbial profile. Body fluid samples such as blood, urine, sputum, bronchoalveolar lavage fluid, tracheal secretions, pus, pleural and peritoneal fluids were sent for culture as indicated on the first day and at anytime during ICU stay if clinically indicated (new onset fever, new chest infiltrates, and hypotension). The time of administration of an antibiotic in relation to the cultures sent were recorded and a note was also kept as to whether this empirical antibiotic was the correct one as compared to the sensitivity pattern in the culture results.

All the data were collected on paper hard copy and fed by computer into a custom built database. The data was checked for inconsistencies and logical errors during entry through programmed range checks and double data entry. Any discrepancy was cross checked against the paper hard copy for accuracy and needed corrections made. All patient personal identifiers were removed from the data files to maintain patient confidentiality. Keeping in tune with the goal of this study, analyses were restricted to univariate analysis to understand the data and bivariate analyses using chi-square tests and t-tests to generate potential hypotheses that would feed into a future advanced analytical/ hypothesis testing study. Univariate analyses used all available information to maximize efficiency. The bivariate analyses for comparing groups / factors were conducted on a trimmed data-set that had complete information on all variables in a "complete case analysis" paradigm. A criterion for statistical significance (alpha) 
was set at $5 \%$ level: i.e. to be statistically significant, the p-value had to be less than 0.05 . All data cleaning and statistical analysis was performed in SPSS (V19).

\section{Results}

The full characteristics of the study population and patients with severe sepsis are described elsewhere [14]. Overall, the characteristics of our severe sepsis cases and ICU outcomes compares well with most international studies though our ICU prevalence of severe sepsis is somewhat lower and mortality rates on the higher sides (Table 1). For the overall study, there were a total of 3010 ICU admissions during the study period.
These included the ones who stayed more than 24 hours in the ICU. There were however 2880 new individual patients and a total of $30(1 \%)$ readmissions. Most were non surgical patients. A total of $292(10.14 \%)$ surgical patients were admitted post surgery. Systemic Inflammatory Response Syndrome (SIRS) without organ dysfunction was found in 2097 (68.75\%) patients while SIRS with organ dysfunction was found in 365 (11.97\%) patients. These patients (SIRS with organ dysfunction) were assessed for severe sepsis. There were 234 patients with severe sepsis due to infection. The mean age of the patients with severe sepsis was $59.19(\mathrm{SD} \pm 18)$ yrs. There were more male patients than female patients (male 58.08\%).

Table 1: Comparison of major epidemiologic studies of severe sepsis including the current study.

\begin{tabular}{|c|c|c|c|c|c|c|c|c|c|}
\hline \multirow{2}{*}{$\begin{array}{l}\text { Study (Ref } \\
\text { number) }\end{array}$} & \multicolumn{3}{|c|}{ Setting } & \multicolumn{2}{|c|}{$\begin{array}{c}\text { Demography of Study } \\
\text { Cohort }\end{array}$} & \multicolumn{3}{|c|}{ Demography of Severe Sepsis Patients } & \multirow{2}{*}{$\begin{array}{c}\text { Hospital } \\
\text { Mortality } \\
\text { (\%) }\end{array}$} \\
\hline & $\begin{array}{l}\text { Time } \\
\text { Frame }\end{array}$ & Region & ICU Type & $\begin{array}{l}\text { Median Age } \\
\text { (yrs) }\end{array}$ & $\begin{array}{c}\text { Male Sex } \\
(\%)\end{array}$ & $\begin{array}{l}\text { Median Age } \\
\text { (yrs) }\end{array}$ & $\begin{array}{c}\text { Male Sex } \\
\text { (\%) }\end{array}$ & $\begin{array}{c}\text { ICU } \\
\text { Prevalence }\end{array}$ & \\
\hline $\begin{array}{c}\text { Current } \\
\text { AMRI } \\
\text { Study (This } \\
\text { study) }\end{array}$ & $\begin{array}{c}\text { Aug } 2006 \\
\text { to Aug } \\
2008\end{array}$ & India & $\begin{array}{l}\text { Medical- } \\
\text { surgical }\end{array}$ & 61 & 58.13 & 62 & 58.8 & 7.77 & 64.6 \\
\hline 3 & $\begin{array}{l}\text { Jan } 1993 \text { to } \\
\text { Apr } 1994\end{array}$ & US & General & NA & NA & 59 & 56 & 10.1 & 34 \\
\hline 5 & 1995 & US & General & NA & NA & 59 & 53 & 11.2 & 34.1 \\
\hline 15 & $\begin{array}{l}\text { May } 1999 \text { to } \\
\text { Jul } 1999\end{array}$ & $\begin{array}{c}\text { Australia } \\
\text { / New } \\
\text { Zealand }\end{array}$ & General & 55.9 & 59.6 & 60.7 & 56.9 & 11.8 & 37.5 \\
\hline 16 & $\begin{array}{l}\text { Jan } 1993 \text { to } \\
\text { Feb } 1993\end{array}$ & France & General & NA & NA & 61.4 & 63 & 9 & 59 \\
\hline 21 & $\begin{array}{l}\text { Nov } 2001 \text { to } \\
\text { Dec } 2001\end{array}$ & France & $\begin{array}{c}\text { General/ } \\
\text { surgical/ } \\
\text { medical }\end{array}$ & 65 & 63 & 70 & 70.1 & 42 & 50 \\
\hline 22 & $\begin{array}{l}\text { May } 2001 \text { to } \\
\text { Jan } 2002\end{array}$ & Brazil & General & 65.2 & 58.7 & 66.4 & 59 & 17.4 & 47.3 \\
\hline 23 & $\begin{array}{l}\text { Dec } 2004 \text { to } \\
\text { Nov } 2005\end{array}$ & China & Surgical & 55 & 58.1 & 64 & 64.8 & 8.68 & 48.7 \\
\hline 24 & $\begin{array}{l}\text { Feb } 1991 \text { to } \\
\text { Jun } 1998\end{array}$ & Germany & Surgical & NA & 64.2 & 61 & 71.3 & 9.4 & 65.5 \\
\hline
\end{tabular}

The predominant site of infection among severe sepsis patients were was the respiratory tract $(57.69 \%)$, mainly due to pneumonia, followed by intra-abdominal (17.95\%), blood stream infection (15.81\%), and urinary tract accounted for $13.25 \%$ of infection. Other sources such as skin, gynecologic, central nervous system, nose, bone-joints and unknown sources together contributed less than $6 \%$ sites. The total is greater than $100 \%$ as more than one site of infection was stated for 11 episodes. The total number of patients admitted to the ICU's with a primary diagnosis of severe sepsis was 209 (89.32\%) while 43 (18.38\%) patients had ICU acquired infection. The 234 patients with severe sepsis suffered 259 episodes of infection. The infections encountered were hospital acquired pneumonia, central line related blood stream infections and urinary tract infections. The prevalence of ventilator associated pneumonia was higher in the general ICUs than in the neurology ICU (data published elsewhere) [14]. We noted very few cases of urinary tract infection in our ICU.

The ICU mortality rate was $12.53 \%$.The standardized mortality ratio was 1.46 . Most of the deaths occurred due to multi-organ failure which was unsupportable $(74.83 \%)$ (Table 2) $\%$. The median predicted death rate was $40 \%$ (IQR $40-55$ ) with an observed death rate of $58.52 \%$. The mortality was high for parasitic infections with mortality of $53.9 \%$ (7 out of 13 ). Five main sepsis related cause of deaths for severe sepsis cases were identified: Sepsis- multiorgan failure (unsupportable) (74.83\%); Sepsis- multiorgan failure (treatment limited or withdrawn) (14.29\%); Respiratory failure (2.72\%); Unheralded cardiac arrest (3.4\%); and Others (Dengue, malaria, hepatic failure) $(4.76 \%)$. Bivariate comparisons of means (t-tests) between clinical outcomes of severe sepsis (death vs. discharged alive) suggested 
that although age, APACHE-II score and number of days in ITU were lower for those discharged alive, they were not statistically significantly different. On an average, the mean number of days on mechanical ventilation was substantially lower for those discharged alive (4.89 days) compared to those who died (7.16 days), the statistical analysis failed to meet a strict significance criteria for alpha $(p=0.05)$ (Table 3). These factors were not different between various attending intensive care doctors managing the patients.

Table 2: Standardized mortality ratio of severe sepsis patients comparing our results to the ANZICS study [23].

\begin{tabular}{|c|c|c|}
\hline Outcome Factor & AMRI & ANZICS \\
\hline $\begin{array}{c}\text { Median Apache II } \\
\text { Score (IQR) }\end{array}$ & $23(22-25)$ & $21(16-26)$ \\
\hline $\begin{array}{c}\text { Median predicted } \\
\text { death rate (IQR) }\end{array}$ & $40(40-55)$ & $38.9(23.5-56.9)$ \\
\hline Observed death rate & 58.52 & 26.5 \\
\hline $\begin{array}{c}\text { Standardized } \\
\text { mortality ratio (SMR) }\end{array}$ & 1.46 & 0.68 \\
\hline
\end{tabular}

Table 3: Means and t-test results for death vs. live discharge from ICU in severe sepsis cases.

\begin{tabular}{|c|c|c|c|}
\hline Factor & Death & $\begin{array}{c}\text { Discharged } \\
\text { Alive }\end{array}$ & P-value \\
\hline Age & $60.03(18.6)$ & $55.14(19.2)$ & 0.15 \\
\hline Apache 2 & $22.52(8.9)$ & $20.18(8.9)$ & 0.16 \\
\hline ITU Days & $9.33(6.5)$ & $9.14(6.7)$ & 0.88 \\
\hline MV Days & $7.16(6.26)$ & $4.89(6.12)$ & 0.05 \\
\hline
\end{tabular}

Table 4: Chi-sq test results, odds ratios and $95 \%$ confidence intervals. For death vs. live discharge from ICU in severe sepsis cases.

\begin{tabular}{|c|c|c|}
\hline Factor & Odds Ratio (95\%CI) & p-value \\
\hline Sex (F/M) & $1.32(0.6,2.8)$ & 0.47 \\
\hline $\begin{array}{c}\text { Blood transfusion } \\
\text { (yes/ no) }\end{array}$ & $2.92(1.4,6.23$ & 0.005 \\
\hline $\begin{array}{c}\text { Mechanical } \\
\text { ventilation (yes/no) }\end{array}$ & $19.51(5.32,71.47)$ & 0 \\
\hline $\begin{array}{c}\text { Procedure in ITU } \\
\text { (yes/ no) }\end{array}$ & $10.03(2.06,48.85)$ & 0.002 \\
\hline $\begin{array}{c}\text { Surgery in ITU (yes/ } \\
\text { no) }\end{array}$ & $1.27(0.37,4.38)$ & 0.71 \\
\hline
\end{tabular}

Further bivariate comparison of other factors measured as categorical variables to assess differences between outcomes of severe sepsis suggested that there were no differences in risk of dying (for those with severe sepsis) between men and women or those undergoing a surgery in the ITU. However, the metrics (crude odds ratio-OR; 95\% confidence interval-CI, and p-value) were statistically significantly different for other factors such as those receiving blood transfusion (OR: 2.92, 95\%CI: 1.4, 6.23; $\mathrm{p}=0.005$ ), mechanical ventilation (OR: 19.51, 95\%CI: 5.32, 71.47; $\mathrm{p}<0.000$ ); and those undergoing some procedure in the ITU (OR: 10.03, 95\%CI: 2.06, 48.85; $\mathrm{p}=0.002$ ) had greater risk of dying (Table 4). These outcomes were not different for the various attending intensive care doctors managing the patients.

\section{Discussion}

Severe sepsis and septic shock remains a treatment challenge with significant morbidity and mortality rates approaching 50\%. Although randomized control trials of potential new therapies are vital in advancing therapeutic option, developing and effective response to the problem of infection and sepsis also relies on the availability of sufficient, up-to-date, epidemiological data about the incidence of the disease, the types of patients affected, specific disease characteristic (e.g. causative microorganism) and outcomes. Such information is vitally important to increase and maintain awareness of the impact of infection and sepsis and to help in the development of local and international policies for diagnosis and treatment. It must be recognized that sepsis and severe sepsis are treated/managed in a variety of ITUS and hospital settings which makes potential "between-ITU variance" an important parameter that may be a major determinant of outcome differences. This possibility makes it important for most large hospitals and ITUs to study the outcomes in their environments and conduct quality assurance procedures to keep associated morbidity and mortality low.

Our preliminary analysis suggests that those severe sepsis patients receiving blood transfusion, mechanical ventilation or some procedure in ITU have a significantly greater risk of dying than those who do not receive these interventions. The median ITU stay of our patients with severe sepsis was 7 days which was similar to that reported by Finfer et al. [15] and the 8.5 days reported by Brun- Buission et al. [16] Patients with severe sepsis in our ICU had a mortality of $58.52 \%$. This was significantly high compared to the $26.5 \%$ rates reported by Finfer et al. [15] and $28 \%$ reported by Angus in their studies. The hospital mortality rate of patients (64.6\%) admitted to ITU with severe sepsis also compared unfavorably with that reported by Finfer et al. [15] (37.5\%) and from the United States (34\%) [17,18].These differences could be attributed to the type and the heterogeneity of patients in the different studies including the case definition criteria and the severity of illness. Other potential factors (not measured/analyzed) may have contributed to the increase in our mortality rate such as: effectiveness of intensive care, effectiveness of post ITU care, inadequacy of antibiotics, late application of an appropriate antibiotic and increasing microbial resistance. Outcomes for various attending doctors were similar, so clinical management paradigms/styles/differences between attending doctors did not contribute to the observed outcome differences.

The presence of an underlying disease, the source and type of infection, presence of shock, multiple organ failure and hospital discharge policies may have also contributed to the increased incidence of sepsis. Ours, being a tertiary hospital, 
patients admitted to our ITUs were usually referred from other centers where the quality of care is unknown and this further compounded the delayed administration of the right antibiotic to such patients. In another study, Sasse et al. [19] noted that acute physiologic derangement, measured by acute physiology score remained strongly associated with mortality up to one month after hospital discharge. In an earlier analysis, we have demonstrated that APACHE score is not a good predictor of length of stay in ITU [20] although it may represents severity of sepsis reasonably well. We calculated the APACHE II score for all our patients within 24 hours of hospital admission and found that it was not co-related with the outcome of severe sepsis. A different kind of microbial flora and possible nosocomial infections of severe sepsis patients in our study are not clearly established (data being analyzed separately and will be published in the future). Higher severe sepsis related mortality in our ITU may probably be a result of complex interactions involving patient's underlying conditions, the characteristics of the patient population, the extensive use of broad-spectrum antibiotics, less attention to sanitary precautions, invasive interventions and the quality of care provided.

The strength of our study lies in its use of high quality data and robust analytical procedures on consecutive admissions in the ITU, allowing use of a precise clinical and physiologic definition of severe sepsis. The potential limitation relates to the use of a relatively small final sample of severe sepsis in one of the most populous countries of the world. We examined only patients treated in the ITU during their ITU admission. Moreover, variation in the availability of ITU resources and variation in practice patterns in end-of-life care may affect the treatment rate of severe sepsis. In India, most of the patients with severe sepsis would be treated in a hospital. However, limited by personal resources, severe sepsis outside the ITU was not investigated in this study, which disenabled the estimation of the treated rate of severe sepsis [21].

\section{Conclusion}

Our study demonstrated that severe sepsis related mortality in our ITU is high and those receiving blood transfusion, mechanical ventilation and some procedure in ITU were at greater risk of death. Diagnosis of sepsis may be problematic because of atypical or nonspecific presentations; biomarkers are of little help at the start of treatment and those too are not specific to sepsis. Severe sepsis is common in the Indian ICUs. Studies should be conducted to establish nationally representative prevalence and incidence rates of sepsis and severe sepsis. With increased internet accessibility and improved information technology, we would be able to compare and combine our data and get a global picture. Analysis of this data and establishing a national registry with adequate data analysis support for sepsis would provide an important resource to develop insights about determining factors causing sepsis and improve its outcome. It will also help in targeting allocation of resources, optimizing healthcare quality, and evaluating the effectiveness and efficiency of ICU utilization.

\section{References}

1. The Seventieth World Health Assembly. Improving the prevention, diagnosis and clinical management of sepsis. 29 May 2017. Available at: http://apps.who.int/gb/ebwha/pdf_files/WHA70/A70_R7-en.pdf. Last accessed March 5th, 2018.

2. American College of Chest Physicians/Society of Critical Care Medicine Consensus Conference: Definitions for sepsis and organ failure and guidelines for the use of innovative therapies in sepsis. Crit Care Med 1992;20:864-874.

3. Sands KE, Bates DW, Lanken PN, Graman PS, Hibberd PL, et al. (1997) Epidemiology of sepsis syndrome in eight academic medical centers. JAMA 279: 234-240.

4. Anderson RN, Smith BL (2003) Deaths: Leading causes for 2001. Natl Vital Stat Rep 52(9): 1-86.

5. Angus DC, Linde ZWT, Lidicker J, Clermont G, Carcillo J, et al. (2001) Epidemiology of severe sepsis in the United States: Analysis of incidence, outcome, and associated costs of care. Crit Care Med 29(7): 1303-1310.

6. Heart Disease and Stroke Statistics - 2004 Update, page 23. American Heart. Association. Available at: http://www.americanheart.org/ downloadable/heart/ 1079736729696HDSStats2004UpdateREV319-04.pdf.

7. Cancer Facts and Figures 2003 (Statistics). American Cancer Society, 2004. Available at: http://www.cancer.org/docroot/STT/stt_0.asp.

8. Acquired immunodeficiency syndrome (AIDS) incidence rates: Erie County, PA and USA (1983-2001). Health Status Indicator Project. Available at: http://www.ecdh.org/documents/AIDS_Incidence.pdf

9. Padkin A, Goldfrad C, Brady A, Young D, Black N, et al. (2003) Epidemiology of severe sepsis occurring in the first $24 \mathrm{~h}$ in intensive care units in England, Wales, and Northern Ireland. Crit Care Med 31(9): 2332-2338.

10. Weycker D, Akhras KS, Edelsberg J, Angus DC, Oster G (2003) Longterm mortality and medical care charges in patients with severe sepsis. Crit Care Med 31(9): 2316-2323.

11. Bernard GR, Vincent JL, Laterre PF, LaRosa SP, Dhainaut JF, et al. (2001) Efficacy and safety of recombinant human activated protein $\mathrm{C}$ for severe sepsis. N Engl J Med 344(10): 699-709.

12. Abraham E (1999) Why immunomodulatory therapies have not worked in sepsis. Intensive Care Med 25(6): 556-566.

13. Bone RC, Balk RA, Cerra FB, Dellinger RP, Fein AM, et al. (1992) Definitions for sepsis and organ failure and guidelines for the use of innovative therapies in sepsis. The ACCP/SCCM Consensus Conference Committee. American College of Chest Physicians/Society of Critical Care Medicine. Chest 101(6): 1644-1655.

14. Chatterjee S (2009) Epidemiology of severe sepsis in the intensive care unit of a tertiary care hospital in Kolkata. Dissertation submitted to The National Board of Examinations, New Delhi, in partial fulfillment towards the requirements for the degree of Diplomate National Board in Family Medicine p. 16.

15. Finfer S, Bellomo R, Lipman J, French C, Dobb G, et al. (2004) Adult population incidence of severe sepsis in Australian and New Zealand intensive care units. Intensive Care Med (2004) 30(4): 589-596.

16. CMA (2001) CMA Medical Data: Directory of Critical Care, CMA Medical Data, Cambridge, UK.

17. Brun BC, Doyon F, Carlet J, Dellamonica P, Gouin F, et al. (1995) Incidence, risk factors, and outcome of severe sepsis and septic shock in adults. A multicenter prospective study in intensive care units. French ICU Group for Severe Sepsis. J Am Med Assoc 274(12): 968-974. 
18. Dellinger RP, Carlet JM, Masur H, Gerlach H, Calandra T, et al. (2004) Surviving Sepsis Campaign guidelines for management of severe sepsis and septic shock. Crit Care Med 32(3): 858-873.

19. Sasse KC, Nauenberg E, Long A, Anton B, Tucker HJ, et al. (1995) Long term survival after intensive care unit admission with sepsis. Crit Care Med 23(6): 1040-1047.

20. Chattopadhyay A, Chatterjee S (2016) Predicting ICU length of stay using APACHE-IV in persons with severe sepsis - a pilot study. Journal of Epidemiological Research 2(1): 1-8.

21. Adrie C, Alberti C, Chaix Couturier C, Azoulay E, De Lassence A, et al. (2005) Epidemiology and economic evaluation of severe sepsis in France: age, severity, infection site, and place of acquisition (community, hospital, or intensive care unit) as determinants of workload and cost. J Crit Care 20(1): 46-58

22. Silva E, Almeida MDP, Sogayar ACB, Mohovic T, Oliveira SDCL, et al (2004) Brazilian Sepsis Epidemiological Study (BASES study). Crit Care 8: R251-R260.

23. Cheng B, Xie G, Yao Sl, Wu X, Guo Q, et al. (2007) Epidemiology of severe sepsis in critically ill surgical patients inten university hospitals in China. Crit Care Med 35(11): 2538-2546.

24. Wichmann MW, Inthorn D, Andress HJ, Schildberg FW (2000) Incidence and mortality of severe sepsis in surgical intensive care patients: the influence of patient gender on disease process and outcome. Intensive Care Med 26(2): 167-172.

Your next submission with Juniper Publishers will reach you the below assets

- Quality Editorial service

- Swift Peer Review

- Reprints availability

- E-prints Service

- Manuscript Podcast for convenient understanding

- Global attainment for your research

- Manuscript accessibility in different formats

( Pdf, E-pub, Full Text, Audio)

- Unceasing customer service

Track the below URL for one-step submission https://juniperpublishers.com/online-submission.php 